\title{
The Relationship between Volume \& Pressure and Rotation \& Torque in Engine Cylinder
}

\section{Run Xu}

Department of Metallurgical Engineering, Gyeongsang National University, Chinju 52828, Korea

DOI: $10.36348 /$ sjet.2020.v05i11.015 $\quad$ | Received: 10.11.2020 | Accepted: 23.11.2020 | Published: 25.11 .2020

*Corresponding author: Run $\mathrm{Xu}$

\section{Abstract}

At 500r/m the volume arrive 1.8E-4 liters which is the biggest one immediately after ignition. Pressure has a small summit when rotation is $2000 \mathrm{r} / \mathrm{m}$. The highest pressure attains $4800 \mathrm{~Pa}$. When the torque is maximum $400 \mathrm{Nm}$ the volume arrives maximum 5E-3liters. Here the correspond rotation this moment is $30 \mathrm{r} / \mathrm{m}$.

Keywords: Pressure; volume; relationship; torque; rotation; engine cylinder.

Copyright ( $) 2020$ The Author(s): This is an open-access article distributed under the terms of the Creative Commons Attribution 4.0 International License (CC BY-NC 4.0) which permits unrestricted use, distribution, and reproduction in any medium for non-commercial use provided the original author and source are credited.

\section{INTRODUCTION}

The fuel performance is searched so that simulation is studied to find the relation of inflamer pressure and volume to rotation and torque in Engine is significant. Among them volume is important inflamer who determines capability, so it needs be studied to look for the internal relation in vehicles [1-3]. Through calculation the volume in engine is successful so we can simulate it through engine cylinder. Meantime the specified emitting is studied to find the quantity of fuel. The temperature may attain two thousand ${ }^{\circ} \mathrm{C}$ which is studied in this paper details. In order to search these respects this paper is simulated and investigated. They are studied quantitively after they are explosion and combustion in engine. It can result in many question in engine. Meantime it has value to control and design more complicated cylinder. To be benefit to our firm use the maximum and minimum gas may be outlet with many vehicles. It is evaluated that one family has a vehicle ie. mainly car in every three families in China. There are about three millions cars in Beijing city. So they are huge discharged gas specially. In this paper we discuss this fuel detail to search their discharged gas quantity and force. We look for this minimum gas method for environment and cost, which is destination.

The parameter of inflamer force is important at engine cylinder of vehicle. It is investigated that it is variable with temperature and cylinder connected shaft force in last paper $[1,2]$. It has significant role in structuring engine internal cylinder simulation and practical parameters. It is to evaluate the inflamer quantity and force from cylinder which includes CO $\mathrm{HC} \& \mathrm{NO}_{x}$ etc inflamer gas in whole in the end. It is convenient for us to control the inflamer and do the prediction and simulate status regardless of experimental measurement. It must connect with these measure later to check its precision to be proven its correct. On the other hand it is investigated what the relationship between volume and rotation is. In this study the relationship between the volume and pressure \& rotation and torque etc.

\section{Modeling Toxic Fuel}

According to ideal gas principle formula

$P V=N R T$.................. (1)

So $d V=N R T d(1 / P)$

And $d P=N R T d(1 / V)$

$N=m / 15$

According to machine principle it has

$T=9.55 \mathrm{~W} / n$

And $v=\frac{\pi d n}{60}$

Here, $\mathrm{N}$ is moles; $\mathrm{T}$ is temperature $\mathrm{K}$; $\mathrm{R}$ is 8.3 $\mathrm{J} /(\mathrm{mol} . \mathrm{K}) ; \mathrm{F}$ is force $\mathrm{N} ; \mathrm{S}$ is square of engine inner square, $\mathrm{m}^{2}, \pi d_{0}^{2} / 4 ; \mathrm{d}$ is engine internal diameter $\mathrm{m} ; \mathrm{V}$ is volume of gas in engine, liters; $\mathrm{n}$ is rotation of engine, $\mathrm{r} / \mathrm{m} ; \mathrm{T}$ is torque of engine, $\mathrm{Nm} ; \mathrm{P}$ is gas pressure , $\mathrm{Pa}$; $\mathrm{W}$ is engine power, $\mathrm{W} ; \mathrm{m}$ is gasoline mass, $\mathrm{Kg}$. 


\section{DISCUSSION}

In terms of above formula and principles the relationship between volume/pressure and rotation, torque \& volume are drawn as below. The two typical and big dependent variable 7.6 liter and 5.8 liter for consuming gasoline per hour are used here to study them. The mass is calculated through them firstly and then compute depending on it respectively. The unit is adopted for common one for correct one the rotation and temperature is adopted for independent variables too. Through regulating them it is drawn to each functional curve for study these parameters and their relationship.

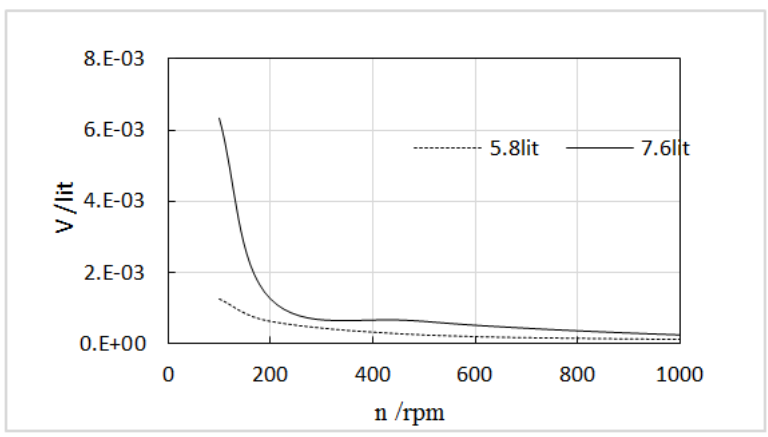

Fig-1: The relationship of volume and rotation in engine cylinder

The volume decreases with the increasing rotation as seen in Figure-1. Meantime volume will be from 1E-3liters to 1E-4liters steeply with rotation increasing to $500 \mathrm{r} / \mathrm{m}$. there is ten times difference between them which expresses that the emitting quantity is controlled at initiate will save more fuel. At $500 \mathrm{r} / \mathrm{m}$ the volume arrive $1.8 \mathrm{E}-4$ liters which is the biggest one immediately after ignition. The volume of 7.6 liter affects lager than that of 5.8liter so that former design will be more sophisticate than later. In order to increase work capability more complicated cylinder demand will be adopted in future. The volume and torque is two needed parameters in near future, so this paper are proceeded for the special parameters. Either to compare with each other value to solve precision difference to predict big need of volume and torque.

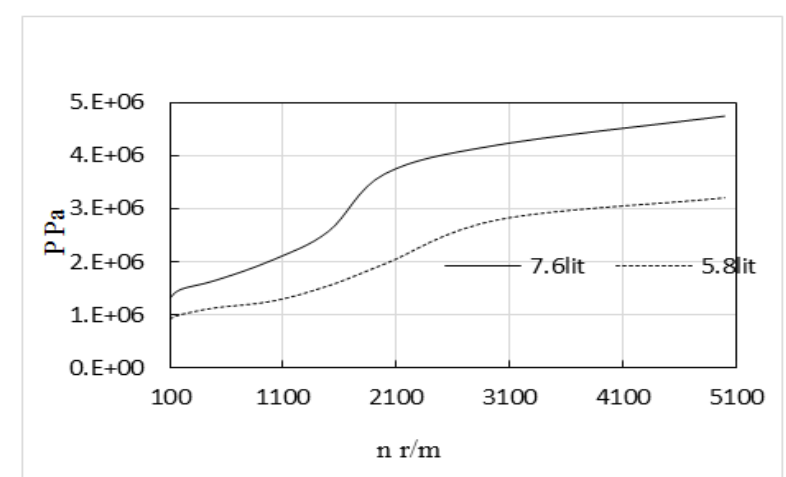

Fig-2: The relationship of pressure and rotation in engine cylinder
As seen in Figure-2 with the increasing rotation the pressure will incline. Meantime there is a little summit when rotation is $2000 \mathrm{r} / \mathrm{m}$. The highest pressure attains $4800 \mathrm{~Pa}$. The pressure with 7.6 liter affects larger than 5.8 liter. The curve like wave meantime the difference of them will be inclined. It expresses that when the rotation inclines the one of 76 liter will sustain the heavier pressure. The construction of engine cylinder will be designed more sophisticate to decline the cost. Such as increasing the internal vessel and promoting the cylinder thickness to support inclined gas pressure.

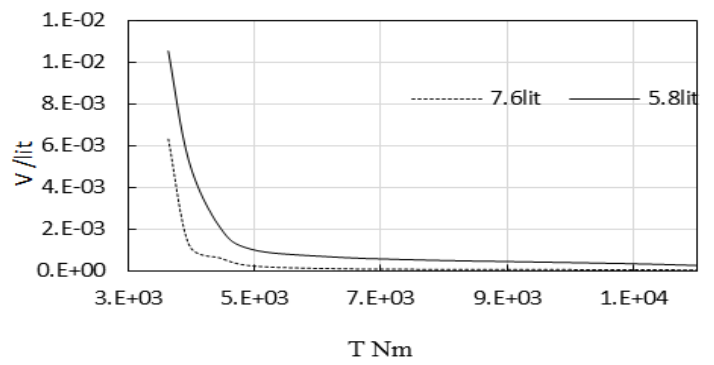

Fig-3: The relationship of volume and torque in engine cylinder

In Figure-3 the volume inclines when the torque increases. It is due to the more torque needing the more fuel. When the torque is maximum $400 \mathrm{Nm}$ the volume arrives maximum 5E-3liters. Here the correspond rotation this moment is $30 \mathrm{r} / \mathrm{m}$. The volume with 5.8 liter becomes bigger than 7.6 liter. So status in 7.6 liter is saver than 5.8 liter as evaluation under a certain torque. The difference of them becomes slightly smaller from $4 \mathrm{E}+3$ to $5 \mathrm{E}+3 \mathrm{Nm}$ and them it is a certain smaller to convergence at infinite big torque. The decreasing cost will be arrived at low temperature and torque field. Here the temperature affects more role on torque than rotation, ie $\mathrm{T}>\mathrm{R}$ in terms of parameter analysis. So when rotation inclines the torque will become big too. In this simulation the force is computed by increasing temperature. So that under rotation increasing the torque will be inclined synchronously.

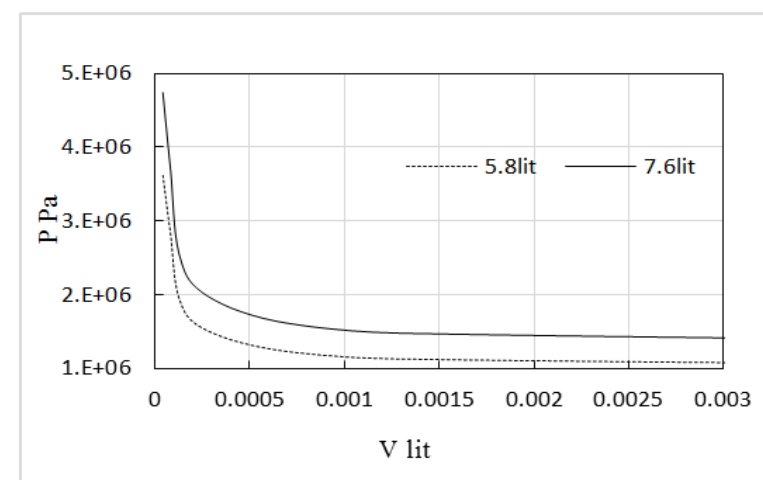

Fig-4: The relationship of pressure and volume in engine cylinder 
In this paper volume $\mathrm{V}$ is the liquid status which is full of engine cylinder to cause the volume change. It is adopted here that $0.015 \mathrm{Kg}$ is the average gas density in cylinder from mixed fuel. From the whole pipe the rule is not deviated it yet. With increasing consuming gas the pressure inclines a certain one so it is considerable the firm engine to use in future under condition of big power and torque. It must be designed the high performance and low cost to satisfy further heavy application. The pressure with 7.6liter is bigger than 5.8liter as principle.

\section{Conclusions}

At $500 \mathrm{r} / \mathrm{m}$ the volume arrive $1.8 \mathrm{E}-4$ liters which is the biggest one immediately after ignition. Pressure has a small summit when rotation is $2000 \mathrm{r} / \mathrm{m}$.
The highest pressure attains $4800 \mathrm{~Pa}$. When the torque is maximum $400 \mathrm{Nm}$ the volume arrives maximum $5 \mathrm{E}$ 3liters. Here the correspond rotation this moment is $30 \mathrm{r} / \mathrm{m}$.

\section{REFERENCES}

1. Run, X. (2020). Simulation of Harmful Fuel Inflamer through Outlet \& Maximum Pressure in Cylinder with Temperature in Engine of Vehicles. Saudi J Eng Technol, 5(10):407-409.

2. Run, X. (2020). The Simulation of Dynamics and Consumed Fuel on Rotary Inertia Vehicles. International Journal of Plant Engineering and Management, 25(2):1-12.

3. Jianhua, W. (2012). Engine Principle of Car. China Machine Press, 110. 